\title{
PENGARUH KOMPENSASI, BUDAYA ORGANISASI DAN KOMITMEN ORGANISASI TERHADAP TURNOVER INTENTION PADA KARYAWAN PT KRAKATAU POSCHEM DONGSHU CHEMICAL
}

\section{THE EFFECT OF COMPENSATION, ORGANIZATIONAL CULTURE AND ORGANIZATIONAL COMMITMENT TO TURNOVER INTENTION IN PT KRAKATAU POSCHEM DONGSHU CHEMICAL}

\section{Deas Faradila, Suryaman}

Program Studi Manajemen, Fakultas Ekonomi dan Bisnis, Universitas Serang Raya deashockey04@gmail.com, unserasuryaman15@gmail.com

\section{Abstract}

Problems: The compensation process, organizational culture, and organizational commitment have a critical role in realizing company goals supported by qualified human resources. Based on preliminary observations at PT Krakatau Poschem Dongshu Chemical, the turnover intention is currently in a high condition because the average score has only reached 36.3 above the standard score of 35 .

Purpose: To find out the effect compensation, organizational culture, and organizational commitment to the turnover intention of PT Krakatau Poschem Dongshu Chemical Cilegon City employees.

Methodology: This research method uses descriptive and associative quantitative methods. The research was conducted from December 2018 to June 2019. The study population was 45 KPDC employees, a sample of 45 people using saturated sampling. Data were collected using research instruments and processed using SPSS statistic version 24.00.

Results/Findings: Compensation, organizational culture, and organizational commitment have a negative and significant effect on turnover intention both partially and jointly at PT Krakatau Poschem Dongshu Chemical, Cilegon City. The results recommend that employee discipline be improved through organizational culture with dimensions of communication patterns limited to formal hierarchical authority.

Paper Type: field research

Keywords: Compensation; Organizational Culture; Organizational Commitment; Turnover Intention 


\section{Abstrak}

Masalah: Proses kompensasi, budaya organisasi dan komitmen organisasi memiliki peran yang sangat penting untuk merealisasikan tujuan perusahaan yang didukung sumber daya manusia yang berkualitas. Berdasarkan observasi awal pada PT Krakatau Poschem Dongshu Chemical turnover intention saat ini pada kondisi tinggi karena nilai rata-rata baru mencapai 36,3 diatas standar skor 35.

Tujuan: Mengetahui pengaruh kompensasi, budaya organisasi dan komitmen organisasi terhadap turnover intention pada karyawan PT Krakatau Poschem Dongshu Chemical Kota Cilegon.

Metodologi: Metode penelitian ini menggunakan metode kuantitatif berjenis deskriptif dan asosiatif. Penelitian dilaksanakan pada bulan Desember 2018 s.d Juni 2019. Populasi penelitian sebanyak 45 karyawan KPDC, sampel sebanyak 45 orang dengan menggunakan sampling jenuh, Data dikumpulkan dengan menggunakan instrumen penelitian dan diolah menggunakan SPSS statistic versi 24.00.

Temuan/Hasil Penelitian: Kompensasi, budaya organisasi dan komitmen organisasi berpengaruh secara negatif dan signifikan terhadap turnover intention baik secara parsial maupun bersama-sama pada PT Krakatau Poschem Dongshu Chemical Kota Cilegon. Hasil penelitian merekomendasikan kedisiplinan karyawan dapat ditingkatkan terutama melalui budaya organisasi dengan dimensi pola komunikasi yang dibatasi pada kewenangan hierarki formal.

Jenis penelitian: Riset lapangan

Kata kunci: Kompensasi; Budaya Organisasi; Komitmen Organisasi; Turnover Intention

\section{A. PENDAHULUAN}

Keberhasilan perusahaan dalam menjalankan usahanya tidak dapat terlepas dari faktor sumber daya manusia (SDM). Terlebih bagi sebuah perusahaan yang menawarkan jasa. Manusia adalah sumber daya yang sangat penting dalam bidang industri dan organisasi (Sunarto, 2020). Pengelolaan sumber daya manusia mencakup penyediaan tenaga kerja yang bermutu, mempertahankan kualitas dan mengendalikan biaya ketenagakerjaan (Sutanto, 2013). Oleh karena itu, SDM adalah aset yang tak ternilai keberadaannya bagi suatu perusahaan sehingga harus dipertahan $\neg$ kan dan dihindari terjadinya turnover.

Berdasarkan observasi awal pada PT Krakatau Poschem Dongshu Chemical, turnover intention saat ini pada kondisi tinggi karena nilai rata-rata baru mencapai 36,3 diatas standar skor 35. Terutama pada karyawan yang menunggu keputusan akan pekerjaan yang lebih baik dengan jumlah skor 42 dan pada karyawan yang ingin mencari pekerjaan baru dengan jumlah skor 41. Secara keseluruhan dapat dikatakan bahwa turnover intention karyawan masih kurang baik. Penelitian ini bertujuan mengetahui pengaruh kompensasi, budaya organisasi dan komitmen organisasi terhadap turnover intention pada karyawan PT Krakatau Poschem Dongshu Chemical Kota Cilegon.

\section{B. KERANGKA TEORI}

\section{Kompensasi}

Kompensasi adalah sesuatu yang dipertimbangkan sebagai balasan suatu pekerjaaan (Ermawati \& Amboningtyas, 2017; Insan \& Yuniawan, 2016). Kompensasi mempunyai dua dimensi yaitu kompensasi langsung yang berupa gaji atau upah dan kompensasi tidak langsung seperti asuransi kesehatan, tunjangan rumah, ataupun bantuan pendidikan (Mangkunegara \& Prabu, 2013) 


\section{Budaya Organisasi}

Budaya organisasi merupakan nilai dan kepercayaan yang berkembang dalam organisasi yang menjadi dasar sikap dan perilaku anggota (Putra, 2015). Budaya organisasi sangat mempengaruhi keber $\neg \neg$ hasilan organisasi dalam mencapai tujuannya. Budaya organi $\neg$ sasi yang kuat akan membentuk karakter anggota yang baik dalam mencapai tujuan perusahaan. Budaya organisasi yang mendukung strategi organisasi dapat menjadi indikator keberhasilan suatu organisasi dalam menghadapi perubahan lingkungan secara tepat dan cepat. Budaya organisasi mempunyai lima dimensi yang dapat digunakan untuk mengidentifikasi beberapa karakteristik (Tan, 2002) yaitu:

1) Individual initiative (tanggung jawab, kebebasan dan kemerdeka $\neg$ an yang dimiliki individu).

2) Risk tolerance (pekerja didorong mengambil resiko, menjadi agresif dan inovatif).

3) Management support (tersedia bantuan, dan dukungan untuk bawahan).

4) Control (jumlah aturan, ketentuan, dan pengawasan langsung terhadap perilaku karyawan)

5) Communication pattern (pola komunikasi dibatasi pada kewenangan hirarki formal.

\section{Komitmen Organisasi}

Komitmen organisasi sebagai suatu komitmen kuat karyawan yang berdampak pada perilaku yang positif terhadap organisasi (Djati \& Khusaini, 2003). Komitmen ini merupakan faktor penting dalam meningkatkan kinerja karyawan dan organisasi (Zia-ud-Din \& Khan, 2010). Komitmen mempresentasikan loyalitas karya $\neg$ wan terhadap organisasi dimana keryawan berada (Rosita \& Yuniati, 2016). Komitmen organisasi mem $\urcorner$ punyai tiga komponen yaitu komponen afektif, komponen normatif dan komitmen berkelanjutan (Meyer \& Allen, 1997).
Komitmen afektif terdiri dari komitmen organisasi yang membuat anggota memiliki keyakinan yang kuat untuk mengikuti segala norma organisasi, komitmen yang terjadi karena ketergantungan terhadap aktivitasaktivitas yang telah dilakukan dalam organisasi pada masa lalu dan hal ini tidak dapat ditinggalkan karena akan merugikan serta komitmen keterlibatan karya $\neg$ wan dalam organisasi. Komitmen Normatif terdiri dari kesetiaan yang diberikan karena pengaruh orang lain dan komitmen yang harus diberikan kepada organisasi.

Komitmen ber $\neg$ kelanjutan memiliki konsep kerugian bila meninggalkan organisasi, komit $\neg$ men karyawan membutuhkan organi ᄀsasi dan komitmen karyawan tetap bekerja dalam organisasi karena karyawan mengakumulasikan manfa $\neg$ at yang lebih yang akan mencegah karyawan mencari pekerjaan lain.

\section{Turnover Intention}

Turnover intention adalah salah satu sikap keluar organisasi untuk mencari kesempatan lain di luar organisasi (Lestari \& Mujiati, 2018). Turnover intention merupakan hak bagi setiap individu dalam menentu-kan masa depannya. Perilaku ini menjadi perhatian penting bagi perusahaan terutama untuk menjaga sumber daya yang berkualitas. Dimensidimensi turnover intention (Lee et al., 2012) terdiri atas :

1) Berpikir untuk keluar (thinking of quitting) yang mencerminkan individu untuk berpikir keluar dari pekerjaan atau tetap berada di tempat kerja.

2) Pencarian alternative (intention to search for alternative) yang mencerminkan individu yang berkeinginan untuk mencari pekerjaan pada organisasi lain.

3) Niat untuk keluar (Intention to quit) yang mencerminkan individu yang berniat untuk keluar.

\section{METODE PENELITIAN}


Penelitian ini mengambil objek penelitian pada PT Krakatau Poschem Dongshu Chemical Kota Cilegon. Penelitian ini bertujuan mengetahui seberapa besar pengaruh kompensasi sebagai independen (X1), Budaya Organisasi sebagai independen (X2) dan komitmen organisasi sebagai independen (X3) terhadap turnover intention karyawan sebagai variabel dependen (Y).

Populasi dalam penelitian ini adalah karyawan PT Krakatau Poschem Dongshu Chemical Kota cilegon. Jumlah karyawan di PT Krakatau Poschem dongshu Chemical sebanyak 45 karyawan tetap. Dalam penelitian ini sampel yang digunakan adalah berdasarkan metode sampling jenuh, yaitu teknik penentuan sampel bila semua anggota populasi digunakan sebagai sampel (Sugiyono, 2011).

\section{HASIL DAN PEMBAHASAN}

Berdasarkan hasil uji validitas memperlihatkan bahwa nilai-nilai koefisien atau rhitung untuk setiap variabel lebih besar dari nilai rtabel, dengan demikian dapat dikatakan bahwa seluruh instrumen dalam penelitian ini bernilai valid (Tabel 1).

Tabel.1

Hasil Uji Validitas

\begin{tabular}{|l|l|l|l|l|l|l|l|l|}
\hline Rtabe & 0,242 & 0,242 & 0,242 & 0,242 & 0,242 & 0,242 & 0,242 & 0,242 \\
\hline KP & 0,589 & 0,682 & 0,709 & 0,641 & 0,711 & 0,709 & 0,664 & 0,681 \\
\hline BO & 0,842 & 0,748 & 0,704 & 0,708 & 0,663 & 0,748 & 0,807 & \\
\hline KO & 0,593 & 0,788 & 0,647 & 0,841 & 0,889 & 0,602 & 0,920 & \\
\hline TI & 0,761 & 0,661 & 0,860 & 0,810 & 0,744 & 0,821 & & \\
\hline
\end{tabular}

Sumber : Hasil Pengolahan Data SPSS V.24.

Uji reliabilitas dilakukan dengan menghitung koefisien alpha cronbach untuk tingkat konsistensi variabel $\mathrm{X}_{1} \mathrm{di}$ dapat nilai alpha sebesar 0,798 dan variabel $\mathrm{X}_{2}$ di dapat nilai alpha sebesar 0,867 dan variabel $X_{3}$ di peroleh nilai alpha sebesar 0,872 dan variabel $\mathrm{Y}$ di peroleh nilai alpha sebesar 0,866, hal ini berarti alpha yang di peroleh dari variabel adalah $>\mathrm{r}$ tabel dan itu artinya bahwa seluruh pernyataan yang terdapat pada kuisioner dapat dinyatakan reliabel.

Analisa deskriptif berdasarkan tanggapan responden bahwa pada prinsipnya kompensasi (X1) termasuk kategori cukup baik karena mempunyai nilai rata-rata 153,2 . Indikator yang paling tinggi dengan skor 184 bahwa perusahaan memberikan program asuransi untuk jaminan kesehatan karyawannya, tapi indikator yang paling rendah yaitu 133 dan 139 bahwa upah yang saya terima sesuai dengan kinerja saya dan saya selalu menerima benefit (keuntungan) dari perusahaan ini.

Analisa deskriptif berdasarkan tanggapan responden bahwa pada prinsipnya budaya organisasi (X2) termasuk kategori cukup baik karna mempunya nilai rata-rata 144,5 sedangkan indikator yang paling tinggi dengan skor 180 bahwa komunikasi organisasi dibatasi oleh hirarki kewenangan formal, tapi indikator yang paling rendah yaitu 128 bahwa atasan memberikan kebebasan kepada saya untuk mengambil keputusan sepanjang hal tersebut dapat dipertanggung jawabkan.

Analisa deskriptif berdasarkan tanggapan responden bahwa pada prinsipnya komitmen organisasi (X3) termasuk kategori baik karena mempunyai nilai rata-rata 168 sedangkan indikator yang paling tinggi dengan skor 185 bahwa saya selalu memprioritaskan tujuan organisasi, tapi indikator yang paling rendah yaitu 135 bahwa perusahaan selalu meng-identifikasi tingkat kelelahan saya dalam bekerja dan saya membutuhkan pekerjaan yang diberikan perusahaan.

Analisa deskriptif berdasarkan tanggapan responden pada prinsipnya turnover intention (Y) termasuk kategori 
rendah karena mempunyai nilai rata-rata 81,5 . Indikator yang paling tinggi dengan skor 91 bahwa saya selalu berpikir untuk keluar dari perusahaan karena tidak puas dengan kompensasi. Budaya organisasi atau komitmen organisasi di perusahaan ini dan indikator terkecil yaitu 76 bahwa saya akan mencari pekerjaan baru.

\section{H-1 Apakah Kompensasi berpengaruh terhadap Turnover Intention karyawan}

Koefisien korelasi kompensasi sebesar -0,234 berada pada posisi 0,200,399 dan mempunyai hubungan yang rendah, artinya nilai kompensasi semakin meningkat maka turnover intention akan semakin rendah. Hasil koefisien regresi variabel kompensasi (X1) sebesar -0,187, sehingga dapat dikatakan bahwa kompensasi (X1) berpengaruh negatif dan signifikan terhadap turnover intention (Y).

Setelah pengujian parsial dilakukan dan diperoleh $\mathrm{dk}=\mathrm{n}-2 \quad(45-2=43)$. Hipotesis dapat diterima jika thitung $>$ ttabel. Berdasarkan tabel anova, diperoleh untuk kompensasi adalah thitung $>$ ttabel $=(-2,601>1,681)$, dengan demikian Hipotesis kompensasi ter-dapat pengaruh negatif dan signifikan antara kompensasi terhadap turnover intention pada Karyawan PT Krakatau Poschem Dongshu Chemical.

\section{H-2 Apakah Budaya Organisasi berpengaruh terhadap Turnover Intention Karyawan}

Hasil dari perhitungan SPSS 24.0 koefisien korelasi budaya organisasi sebesar -0,329 berada pada posisi 0,200,399 dan mempunyai tingkat hubung $7 a n$ yang rendah, artinya nilai budaya organisasi semakin meningkat maka turnover intention akan semakin rendah. Berdasarkan Asosiatif bahwa hipotesis 1 dengan hasil koefisien regresi variabel kompensasi (X2) sebesar -0,276, sehingga dapat dikatakan bahwa budaya organisasi (X2) berpengaruh negatif signifikan terhadap turnover intention $(\mathrm{Y})$.
Setelah pengujian parsial dilakukan dan diperoleh $\mathrm{dk}=\mathrm{n}-2(45-2=43)$. Hipotesis dapat diterima jika thitung>ttabel. Berdasarkan tabel anova diatas, diperoleh untuk kompensasi adalah thitung $>$ ttabel $=(-3,270>1,681)$, dengan demikian Hipotesis budaya organisasi terdapat pengaruh negatif dan signifikan antara budaya organisasi terhadap turnover intention pada Karyawan PT Krakatau Poschem Dongshu Chemical.

\section{H-3 Apakah Komitmen Organisasi berpengaruh terhadap Turnover Intention Karyawan}

Hasil dari perhitungan SPSS 24.0 koefisien korelasi komitmen organisasi sebesar -0,446 berada pada posisi 0,400,599 dan mempunyai tingkat hubungan yang sedang, artinya nilai komitmen organisasi semakin meningkat maka turnover intention akan semakin menurun. Hipotesis 1 dengan hasil koefisien regresi variabel komitmen organisasi (X3) sebesar $-0,349$, sehingga dapat dikatakan bahwa komitmen organisasi (X3) berpengaruh negatif dan signifikan terhadap turnover intention (Y).

Setelah pengujian parsial dilakukan dan diperoleh $\mathrm{dk}=\mathrm{n}-2(45-2=43)$. Hipotesis dapat diterima jika thitung>ttabel. Berdasarkan tabel anova diatas, diperoleh untuk komitmen organisasi adalah thitung $<$ ttabel $=(-4,904$ $<$ 1,681), dengan demikian Hipotesis komitmen organisasi terdapat pengaruh negatif dan signifikan antara komitmen organisasi terhadap turnover intention pada Karyawan PT Krakatau Poschem Dongshu Chemical.

\section{H-4 Apakah Pengaruh Kompensasi, Budaya Organisasi dan Komitmen Organisasi Terhadap Turnover Intention Karyawan}

Berdasarkan Asosiatif bahwa hipotesis 3 dengan hasil koefisien determinasi variabel kompensasi (X1), 
budaya organisasi (X2) dan komitmen organisasi (X3) secara simultan sebesar $0,420(42 \%)$ dan sisanya 0,58 (58\%) dipengaruhi faktor lain yang tidak diteliti oleh penulis. Setelah pengujian simultan dilakukan, maka diperoleh $\mathrm{df}=45-3-1=$ $42(\mathrm{df}=\mathrm{n}-\mathrm{k}-1)$. Hipotesis dapat diterima jika Fhitung $>$ Ftabel. Berdasarkan tabel anova, diperoleh kinerja pegawai adalah $(11,623>2,83)$ dan nilai signifikansi adalah sebesar 0,000 0,05 maka dapat disimpulkan bahwa Ho ditolak dan $\mathrm{Ha}$ diterima, dengan demikian Hipotesis terdapat pengaruh negatif dan signifikan antara kompensasi, budaya organisasi dan komitmen organisasi secara bersama-sama terhadap turnover intention pada karyawan PT Krakatau Poschem Dongshu Chemical, dengan demikian nilai kompensasi dan budaya organisasi secara bersama-sama akan semakin meningkat maka turnover intention menurun.

\section{E. PENUTUP}

Berdasarkan hasil analisis dan pembahasan, tentang Pengaruh kompensasi, budaya organisasi dan komitmen organisasi terhadap turnover intention pada karyawan PT Krakatau Poschem Dongshu Chemical penulis menarik kesimpulan bahwa kompensasi berpengaruh negatif dan signifikan secara parsial terhadap turnover intention pada karyawan PT Krakatau Poschem Dongshu Chemical Budaya organisasi berpengaruh negatif dan signifikan secara parsial terhadap turnover intention pada karyawan Komitmen organisasi berpengaruh negatif dan signifikan terhadap turnover intention pada karyawan Kompensasi, budaya organisasi dan komitmen organisasi berpengaruh negatif dan signifikan sebesar 42,1\% secara simultan.

Kompensasi termasuk kategori cukup baik, karena rata-rata skor 153,2. Adapun yang perlu dipertahan-kan oleh perusahaan yaitu perusahaan memberikan asuransi untuk jaminan kesehatan karyawannya dan juga perusahaan disarankan untuk mem-per $\neg$ hitungkan penetapan upah sesuai dengan azas kinerja karyawan yang sesuai. Budaya organisasi termasuk kategori cukup baik, karena ratarata skor 144,5 .

Adapun yang perlu dipertahankan oleh perusahaan yaitu mempertahankan komunikasi organi-sasi dibatasi oleh hirarki kewenangan formal dan disarankan agar atasan memberikan toleransi kepada karyawan $\neg$ na untuk mengambil keputusan sepanjang hal tersebut dapat dipertanggung jawabkan. Komitmen organisasi termasuk kategori baik, karena rata-rata skor 168. Adapun yang perlu dipertahankan oleh manajerial yaitu membuat agar karyawannya selalu memprioritaskan tujuan organisasi dan juga disarankan agar perusahaan selalu mengiden $\neg$ tifikasi tingkat kelelahan karyawannya saat dalam bekerja.

\section{DAFTAR PUSTAKA}

Djati, S. P., \& Khusaini, M. K. M. (2003). Kajian terhadap kepuasan kompensasi, komitmen organisasi, dan prestasi kerja. Jurnal Manajemen Dan Kewirausahaan, 5(1), 25-41. https://ojs.petra.ac.id/ojsnew/index.p $\mathrm{hp} / \mathrm{man} /$ article/view/15631

Ermawati, Y., \& Amboningtyas, D. (2017). Pengaruh Motivasi Intrinsik, Komunikasi, Dan Kompensasi Finansial Terhadap Kinerja Karyawan Produksi Video Preparation Pada PT HIT Polytron yang Berimplikasi pada Produktivitas. Journal of Management, 3(3), 201-220. http://jurnal.unmuhjember.ac.id/inde x.php/JMBI/article/view/24/21

Insan, P. D., \& Yuniawan, A. (2016). Pengaruh Gaya Kepemimpinan Partisipatif, Lingkungan Kerja, Kompensasi Dan Budaya Organisasi Terhadap Kinerja Karyawan (Studi 
Pada Bagian Keperawatan Rsud Tugurejo Semarang). Diponegoro Journal of Management, 5(1), 40-52. https://ejournal3.undip.ac.id/index.ph $\mathrm{p} /$ djom/article/view/13438

Lee, C.-C., Huang, S.-H., \& Zhao, C.-Y. (2012). A study on factors affecting turnover intention of hotel empolyees. Asian Economic and Financial Review, 2(7), $\begin{array}{llllll}8 & 6 & 6 & 8 & 7\end{array}$. http: / / www.aessweb.com /pdffiles/866-875.pdf

Lestari, N. N. Y. S., \& Mujiati, N. W. (2018). Pengaruh Stres Kerja, Komitmen Organisasi, dan Kepuasan Kerja Karyawan terhadap Turnover Intention. E-Jurnal Manajemen Universitas Udayana, 7(6), 3412-3441. https://doi.org/10.24843/EJMUNUD.2 018.v07.i06.p20

Mangkunegara, A. P., \& Prabu, A. (2013). Manajemen Sumber Daya Manusia Perusahaan. Bandung: PT Remaja Rosda Karya Bandung.

Meyer, J. P., \& Allen, N. J. (1997). Commitment in the Workplace: Theory, Research, and Application. SAGE

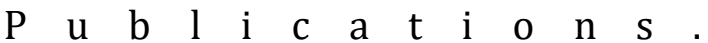
https://books.google.co.id/books?id= WPQoCgAAQBAJ

Putra, S. W. (2015). Pengaruh komitmen organisasi, budaya organisasi, gaya kepemimpinan dan lingkungan terhadap kinerja karyawan pada industri kecil. Jurnal Ekonomi MODERNISASI, $\quad 11(1), \quad 62$. https://doi.org/10.21067/jem.v11i1.8 69

Rosita, T., \& Yuniati, T. (2016). Pengaruh kepuasan kerja terhadap kinerja karyawan dengan komitmen organisasional sebagai variabel intervening. Jurnal Ilmu Dan Riset Manajemen (JIRM), 5(1), 1-20. http://jurnalmahasiswa.stiesia.ac.id/in dex.php/jirm/article/view/422

Sugiyono. (2011). Metodologi penelitian kuantitatif kualitatif dan R\&D. Bandung: Alfabeta.

Sunarto, A. (2020). Pengembangan Sumber Daya Manusia dengan Berbasis Inovasi Untuk Menghadapi Revolusi Industri 4.0. Jurnal Ilmiah MEA (Manajemen, Ekonomi, \& Akuntansi), 4(2), 397-407. http://www.journal.stiemb.ac.id/index .php/mea/article/view/504

Sutanto, G. (2013). Hubungan adversity quotient dengan intensi turnover pada karyawan BRI kantor cabang Malang Martadinata. Skripsi. Universitas Negeri Malang]. http://repository.um.ac.id/id/eprint/1 00852

Tan, V. S. L. (2002). Changing your corporate culture: The key to surviving tough times. Times Books International.

Zia-ud-Din, \& Khan, M. R. (2010). The Impact of Organizational Commitment on Employees Job Performance: 'A Study of Oil and Gas Sector of Pakistan.' SSRN Electronic Journal. https://doi.org/10.2139/ssrn.157054 4 